\title{
Time course of necrotizing hepatopancreatitis (NHP) in experimentally infected Litopenaeus vannamei and quantification of NHP-bacterium using real-time PCR
}

\author{
Amanda G. Vincent, Jeffrey M. Lotz* \\ Department of Coastal Sciences, The University of Southern Mississippi, Gulf Coast Research Laboratory, PO Box 7000 , \\ Ocean Springs, Mississippi 39566-7000, USA
}

\begin{abstract}
Necrotizing hepatopancreatitis (NHP), a severe bacterial disease affecting penaeid shrimp aquaculture, is caused by a gram-negative, pleomorphic, intracellular $\alpha$-proteobacterium referred to as the NHP-bacterium (NHPB). The time course of NHP was investigated in experimentally infected juveniles of Kona stock Litopenaeus vannamei. Susceptible animals were individually isolated in $4 \mathrm{l}$ of aerated artificial seawater at salinity $30 \pm 1 \mathrm{ppt}$ and maintained in a water bath at $30 \pm$ $1^{\circ} \mathrm{C}$ for $60 \mathrm{~d}$. A total of 120 individuals were exposed per os to a $0.05 \mathrm{~g}$ piece of NHPB-infected hepatopancreas and 100 controls were exposed to uninfected tissue. At intervals of 3, 6, 9, 16, 23, 30, 37, 44, and 53 d post-exposure, 6 shrimp exposed to NHPB-infected tissue and 4 controls were randomly removed from the experiment; hepatopancreas samples were processed for histological and molecular analysis, and feces were processed for molecular diagnosis of NHPB infection. NHPB was first detected in the hepatopancreas through histology at $6 \mathrm{~d}$ post-exposure. All control shrimp were diagnosed as NHPB negative. NHPB infections classified as stage I (scattering of hepatopancreatic tubules with adjacent epithelial cells containing NHPB) and stage II (numerous infected tubules with occasional hemocyte infiltration) were observed from 6 to $37 \mathrm{~d}$ post-exposure. All animals that experienced NHPB-induced mortality from 16 to $51 \mathrm{~d}$ post-exposure were at stage III (numerous necrotic tubules, dense hemocyte infiltration, and presence of granulomas). NHPB is capable of infecting all hepatopancreatic cell types including embryonic, resorptive, fibrillar and blister-like cells. The percent of hepatopancreatic tubules containing NHPB in epithelial cells increased over time, representing bacteria multiplication and spread. Real-time PCR allowed for quantification of NHPB in

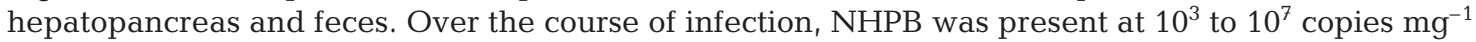
of hepatopancreas and $10^{1}$ to $10^{5}$ copies $\mathrm{mg}^{-1}$ of feces. Lethal infections contained $10^{6}$ to $10^{7}$ copies $\mathrm{mg}^{-1}$ of hepatopancreas and $10^{3}$ to $10^{6}$ copies $\mathrm{mg}^{-1}$ of feces.
\end{abstract}

KEY WORDS: Necrotizing hepatopancreatitis $\cdot$ Litopenaeus vannamei $\cdot$ Real-time PCR $\cdot$ Shrimp diseases $\cdot$ Aquaculture

Resale or republication not permitted without written consent of the publisher

\section{INTRODUCTION}

Necrotizing hepatopancreatitis (NHP) was first observed in Texas, USA, in 1985 and subsequently in several South American countries, e.g. Peru, Ecuador, Venezuela, Brazil, and Panama. NHP is a severe disease in penaeid shrimp causing up to $95 \%$ mortality in affected ponds (Johnson 1990, Lightner 1996). Elevated salinity and temperature are considered risk factors that greatly influence the occurrence of NHP (Frelier et al. 1992, Lightner \& Redman 1994, Lightner 1996). Reported host species for NHP are Litopenaeus vannamei, L. setiferus, L. stylirostris, Farfantepenaeus aztecus and F. californiensis (Lightner 1996).

The NHP-bacterium (NHPB) is the causative agent of NHP. NHPB is a member of the $\alpha$-subclass of proteobacteria and is a gram-negative, pleomorphic, obligate intracellular rickettsia-like pathogen. It is 
present in 2 distinct morphological forms, a predominant rod form and a flagellated helical form (Krol et al. 1991, Frelier et al. 1992, Lightner et al. 1992). NHPB targets host hepatopancreas tissue, the only reported site of NHPB infection. Animals infected with NHPB characteristically display reduced feed intake, empty mid- and hind-guts, soft shells, flaccid bodies, and lethargy. The hepatopancreas of NHPB-infected shrimp displays marked atrophy and may appear pale with a whitish center. Melanization of hepatopancreatic tubules and numerous granulomas have been observed in severe NHPB infections (Lightner 1996).

Several diagnostic methods are available for detection of NHPB in shrimp including histology, in situ hybridization, and PCR (Lightner 1996, Loy \& Frelier 1996, Loy et al. 1996a,b). Monoclonal antibodies have been developed for NHPB detection (Bradley-Dunlop et al. 2004). Briñez et al. (2003) report detection of NHPB DNA in fecal samples of Litopenaeus vannamei adults, thus providing a non-destructive method for NHPB diagnosis of infected broodstock. However, there are no reported non-invasive sampling methods for diagnosis of NHPB in post-larvae or juvenile penaeid shrimp. Varner (1998) failed to detect NHPB in post-larvae of $L$. vannamei and suggested the presence of PCR inhibitors or the instability of NHPB in the external environment may be the cause.

Frelier et al. (1992) classified development of NHP infection in penaeid shrimp into 3 stages. Stage I is characterized by scattered hepatopancreatic tubules exhibiting groups of cells containing intracellular bacteria but lacking interstitial hemocytic infiltration. Stage II is characterized by numerous hepatopancreatic tubules lined by either hypertrophic or attenuated epithelium with tubular ectasia, few necrotic tubules, some luminal desquamation of epithelial cells, and occasional hemocyte infiltration. Stage III is characterized by numerous necrotic hepatopancreatic tubules lacking intact epithelium and desquamated epithelia cells, dense hemocyte infiltration, melanization, and fibriosis. A decreased lipid content of the hepatopancreas is progressively observed from stage I to III of NHP disease.

The purpose of this research is to evaluate the course of NHPB infection in Litopenaeus vannamei over time with the following aims: (1) to determine which hepatopancreas epithelial cell types NHPB is capable of infecting; (2) to characterize the post-exposure timing of NHP disease stages I, II, or III as classified by Frelier et al. (1992); (3) to present a non-invasive method for diagnosing NHPB infection in live juveniles using feces as a DNA source of NHPB; (4) to quantify NHPB in shrimp tissue using a novel real-time PCR procedure; and (5) to compare sensitivities of current diagnostic tools for early detection of NHPB.

\section{MATERIALS AND METHODS}

Experimental design. A total of 220 juveniles of Kona stock Litopenaeus vannamei of mean weight $5.7 \mathrm{~g}$ (range 3.0 to $8.8 \mathrm{~g}$ ) were individually placed in aerated Sterilite ${ }^{\circledR}$ containers ( $35 \mathrm{~cm}$ long by $22 \mathrm{~cm}$ wide by $12 \mathrm{~cm}$ high). Kona stock $L$. vannamei are from a specific pathogen free population available through the United States Marine Shrimp Farming Program (Pruder et al. 1995, Lotz et al. 2003). Shrimp were maintained at a depth of $9 \mathrm{~cm}$ using artificial Crystal Sea ${ }^{\circledR}$ Marinemix seawater at salinity $30 \pm 1$ ppt prepared from reverse osmosis filtered water to a total volume of approximately $4 \mathrm{l}$. The NHP-bacterium is unculturable through traditional bacteriological methods, thus NHPB infection must be maintained through continuous exposure of uninfected Kona stock L. vannamei to a population undergoing an NHPB epidemic. Shrimp showing gross signs of NHPB infection were obtained from the long-term maintenance system described by Vincent et al. (2004) for NHPB exposure to $L$. vannamei. The hepatopancreas of NHPB-infected shrimp was excised, weighed to the nearest $0.01 \mathrm{~g}$, and divided into 4 approximately $0.05 \mathrm{~g}$ sections. Uninfected shrimp fasted for $3 \mathrm{~d}$ were fed a $0.05 \mathrm{~g}$ piece of an NHPB-infected hepatopancreas; 120 shrimp were exposed to NHPB-infected material and 100 control shrimp were exposed to NHPB-negative material prepared from uninfected shrimp hepatopancreas.

Individual shrimp ingested the $0.05 \mathrm{~g}$ piece of hepatopancreas within $1 \mathrm{~h}$. Shrimp were maintained in a water bath at $30 \pm 1^{\circ} \mathrm{C}$ for $60 \mathrm{~d}$ and freshwater was added to the individual containers only to replace evaporation. Temperature was monitored daily and salinity weekly. Water quality of individual tanks was acceptable. Individual shrimp were fed commercial pellets at approximately $5 \%$ body weight every other day.

The day of post-exposure mortality was recorded for all shrimp that died within the $60 \mathrm{~d}$ period. Based on previous observation of the course of NHPB infection in Kona stock Litopenaeus vannamei, 6 live shrimp exposed per os to NHPB-infected material and 4 shrimp exposed to uninfected material were randomly removed from the experiment at intervals of $3,6,9,16$, $23,30,37,44$, and $53 \mathrm{~d}$ post-exposure and processed for molecular and histological examination for NHPB infection. Shrimp were cut transversely at the junction of the cephalothorax and abdomen and a small piece of the hepatopancreas of approximately $25 \mathrm{mg}$ was excised from the posterior portion of the cephalothorax and stored in a $1.5 \mathrm{ml}$ microcentrifuge tube at $-20^{\circ} \mathrm{C}$ for PCR analysis. Feces were either collected from the container that housed the respective individual using a $1 \mathrm{ml}$ disposable pipette, or extracted from the midand hind-gut of the shrimp. Approximately $250 \mathrm{mg}$ of 
feces from each shrimp was placed in a $1.5 \mathrm{ml}$ microcentrifuge tube and stored at $-20^{\circ} \mathrm{C}$ for PCR analysis. NHPB DNA in hepatopancreas and fecal samples for each individual was extracted (Loy et al. 1996a) and analyzed by PCR (DiagXotics ${ }^{\circledR}$ ) targeting a 312 bp amplicon.

Davidson's alcohol-formalin-acetic acid (AFA) fixative was injected into each cephalothorax to ensure thorough fixation of the remaining hepatopancreas. The cephalothorax was immersed in Davidson's AFA for 48 to $72 \mathrm{~h}$, then cut along the sagittal plane, placed in Tissue-Tek ${ }^{\circledR}$ uni-cassettes, and stored in $70 \%$ ethanol prior to paraffin embedding and sectioning at $5 \mu \mathrm{m}$. Sections of paraffin embedded tissue were examined for NHPB infection by routine hematoxylin and eosin staining and a modified Steiner-Steiner silver stain (Sigma, HT101A) (Lightner 1996). At the end of the $60 \mathrm{~d}$ exposure period, all shrimp were killed and processed in like manner.

The percent of hepatopancreatic tubules containing NHPB was estimated for exposed animals by counting the number of tubules containing intracytoplasmic NHPB in epithelial cells and of uninfected tubules present in a section of hepatopancreas stained by a modified Steiner-Steiner silver stain. Epithelial cells containing intracytoplasmic NHPB stained black, whereas cells not containing NHPB stained brown. The percent of hepatopancreatic tubules containing NHPB was obtained by dividing the number of NHPB infected tubules by the total tubules present in a tissue section.

Real-time PCR. Primers and TaqMan probe specific for NHPB were selected based on the NHPB genomic sequence provided by Loy et al. (1996a) (GenBank accession number U65509). PCR primers and TaqMan probe were designed using Beacon Designer 2 software (PREMIER Biosoft International). Forward primer 'NHPB396F' sequence is 5'-CGATAATGACGGTAGCAGGACAA-3' (23 bp length) and corresponds to nucleotides 396 through 418 of the $1415 \mathrm{bp}$ published NHPB genomic sequence. Reverse primer 'NHPB539R' sequence is 5'-CCCAGGGCTTTCACACCTTG-3' (20 bp length) and corresponds to nucleotides 539 to 520 on the reverse strand. The TaqMan probe 'NHPBPrb' sequence is 5'-CTGGGCGTAAAGGGTGCGTAGGCG-3' (24 bp length) and corresponds to nucleotides 486 to 509 on the forward strand. The TaqMan probe is labeled on the 5' end with 5-carboxyfluoroscein (FAM) and on the $3^{\prime}$ end with $\mathrm{N}, \mathrm{N}, \mathrm{N}^{\prime}, \mathrm{N}^{\prime}$ tetramethyl-6-carboxyrhodamine (TAMRA). The target sequence is $144 \mathrm{bp}$ in length and corresponds to nucleotides 396 to 539 in the published genomic sequence of NHPB.

Real-time PCR reactions were conducted on a total volume of $25 \mu \mathrm{l}$. The reaction mixture consisted of $3.0 \mu \mathrm{l}$ sterile water, $2.5 \mu \mathrm{l}$ of Taq DNA Polymerase 10×
Buffer with $15 \mathrm{mM}$ of $\mathrm{MgCl}_{2}$ (Promega), $0.5 \mu \mathrm{l}$ of $10 \mathrm{mM}$ PCR nucleotide mix (Promega), $2.0 \mu \mathrm{l}$ of $3.0 \mu \mathrm{M}$ 'NHPB396F' forward primer (Invitrogen), $2.0 \mu \mathrm{l}$ of $3.0 \mu \mathrm{M}$ 'NHPB539R' reverse primer (Invitrogen), $2.0 \mu \mathrm{l}$ of $25 \mathrm{mM} \mathrm{MgCl}_{2}$ (Amersham Pharmacia Biotech) for a total of $35 \mathrm{mM} \mathrm{MgCl}_{2}$ in the reaction, $5.0 \mu \mathrm{l}$ of an additive reagent (Bovine Serum Albumin non-acetylated aqueous solution, Sigma B-8667; Trehalose from Saccharomyces cerevisiae, Sigma T-9531; Tween-20 Polyoxethylene Sorbitan Monolaurate, Pierce 28320; and $1 \mathrm{M}$ Tris buffer $\mathrm{pH}$ 8.0, BioWhitaker 16-015Y) at $5 \times$ concentration, $2.5 \mu \mathrm{l}$ of $1.5 \mu \mathrm{M}$ of the TaqMan probe 'NHPBPrb' (Integrated DNA Technologies), $0.5 \mu \mathrm{l}$ of $5 \mathrm{U}^{-1}$ Taq DNA Polymerase (Promega) and $5 \mu \mathrm{l}$ of sample template DNA.

Real-time PCR reactions were incubated at $94^{\circ} \mathrm{C}$ for $300 \mathrm{~s}$ followed by 45 cycles of 2-step amplification at $94^{\circ} \mathrm{C}$ for $5 \mathrm{~s}$ and $60^{\circ} \mathrm{C}$ for $30 \mathrm{~s}$ (Jiang et al. 2003) on a Cepheid Smart Cycler (Cepheid). All samples were replicated twice and the mean and standard error of the copy number calculated for each sample using Systat 11 (SYSTAT Software).

The standard for real-time PCR is an oligonucleotide sequence of $150 \mathrm{bp}$ corresponding to nucleotides 393 to 542 in the published genomic sequence of NHPB. The $150 \mathrm{bp}$ standard sequence (TriLink Biotechnologies) encompasses the $144 \mathrm{bp}$ target of real-time PCR. The $150 \mathrm{bp}$ oligonucleotide is approximately $99 \mathrm{kdal}$. Multiplying the molecular weight by the inverse of Avogadro's number gives $1.64 \times 10^{-19} \mathrm{~g} \mathrm{copy}^{-1}, 6.1 \times$ $10^{18}$ copies g $^{-1}$, and $6.1 \times 10^{9}$ copies ng $^{-1}$ (Tang \& Lightner 2001, Whelan et al. 2003). The oligonucleotide standard was stored in aliquots of $10^{14}$ copies in TrisEDTA buffer, serially diluted prior to real-time PCR, and used to generate standard curves.

To determine variability present in real-time PCR, replicated sets of nested samples were evaluated: hepatopancreases from 3 shrimp were used to estimate variation across hepatopancreases from different shrimp, 3 pieces of each hepatopancreas to estimate variation within a hepatopancreas, 3 extractions of each hepatopancreas piece to estimate variation due to extraction, and $3 \mathrm{PCR}$ reactions of each extraction to estimate variation due to real-time PCR.

Three individuals displaying gross signs of NHPB infection were removed from the NHPB/Litopenaeus vannamei long-term maintenance system (Vincent et al. 2004). Each shrimp was cut transversely at the junction of the cephalothorax and abdomen and the hepatopancreas removed. Each hepatopancreas was divided into 3 pieces and each piece was placed in a $1.5 \mathrm{ml}$ microcentrifuge tube and stored at $-20^{\circ} \mathrm{C}$. Prior to extraction and purification of NHPB DNA, each hepatopancreas piece was divided into a sub-sample of 3 smaller pieces. After DNA extraction each sub- 
sample was replicated 3 times at 1:100 dilution then each diluted replicate was analyzed through real-time PCR 3 times.

The coefficients of variation about the threshold cycles of real-time PCR specific for NHPB were obtained (1) for samples obtained from a single shrimp, (2) for extraction of DNA, (3) for dilution of extracted DNA, and (4) within dilution variability in the real-time PCR reactions and box plots graphed in Systat 11.

\section{RESULTS}

\section{Time course of NHP}

NHPB was observed in resorptive (R), fibrillar $(\mathrm{F})$ and blister-like (B) cells at $6 \mathrm{~d}$ post-exposure. The infected tubules were located in the proximal portion of the hepatopancreas, therefore no embryonic (E) cells were observed harboring NHPB. E-cells were first observed harboring NHPB at 19 d post-exposure in lethal infections. At 6 d, single scattered tubules were usually infected with NHPB. Frequently, in early NHPB infections, an infected tubule would be surrounded by many uninfected tubules. At $23 \mathrm{~d}$, NHPBinfected tubules were often surrounded by groups of other infected tubules.

From Day 6 to Day 23, less than 1\% of the hepatopancreatic tubules contained NHPB. An increase in the number of tubules containing NHPB infected cells occurred from Day 23 to 37 when prevalence of infected tubules was 21 to $85 \%$. In shrimp experiencing NHPB-induced mortality, 90 to $100 \%$ of the hepatopancreatic tubules were infected.

Histological examination revealed that stage I occurred from 6 to $23 \mathrm{~d}$ post-exposure (Fig. 1). Stage II was observed 16 to $37 \mathrm{~d}$ post-exposure. Stage III occurred at 16 to $51 \mathrm{~d}$ post-exposure and coincided with mortalities and hemocyte infiltration and granuloma formation. All shrimp that experienced NHPBinduced mortality were in stage III.

\section{Real-time PCR}

A known quantity of the $150 \mathrm{bp}$ NHPB standard sequence was employed to generate standard curves $\left(\mathrm{R}^{2}=0.99\right)$ for quantification of NHPB in hepatopancreas and feces. The standard was serially diluted to contain from $1.4 \times 10^{8}$ to $1.4 \times 10^{3}$ copies $5 \mathrm{\mu l}^{-1}$. The detection limit is 10 copies of NHPB DNA.

The variability observed in real-time PCR is presented in Fig. 2. The median coefficient of variation about the threshold cycle was highest among hepatopancreas samples from different shrimp (0.044).

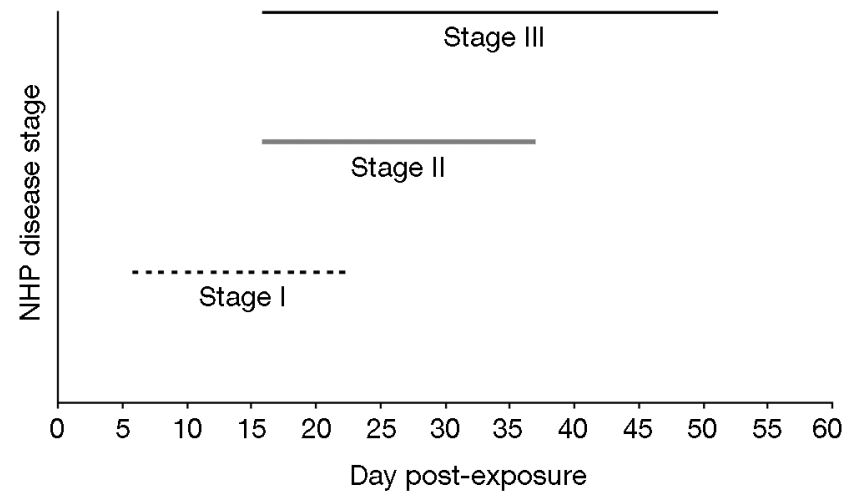

Fig. 1. Litopenaeus vannamei. Periods of observed NHP disease stage I, II, and III over the course of NHPB infection. Stage I is marked by scattered tubules with adjacent epithelial cells containing intracytoplasmic NHPB, stage II by epithelial cells pulling away from tubule and basophilic cytoplasm containing NHPB, and stage III marked by hemocyte infiltration, necrotic tubules, melanization, and fibriosis (Frelier et al. 1992)

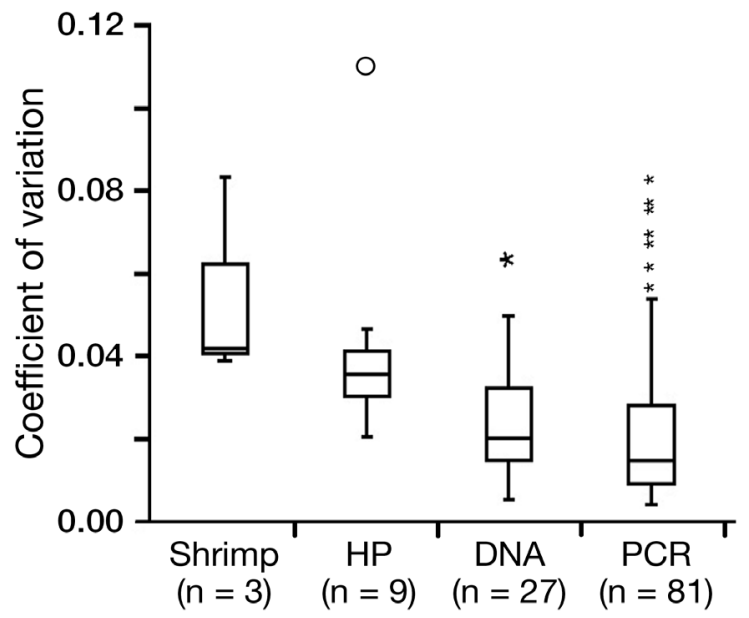

Fig. 2. Litopenaeus vannamei. Box-plots of coefficients of variation of hepatopancreas samples from different shrimp $(n=3), 3$ pieces of each shrimp's hepatopancreas (HP) $(n=9)$, 3 separate extractions from the 3 hepatopancreas pieces $(\mathrm{n}=27)$, and same tube replicates of real-time PCR $(\mathrm{n}=81)$. Asterisks denote outliers; circle denotes far outlier

The lowest median coefficient of variation was observed among real-time PCR reactions from the same reaction tube replications (0.013).

Real-time PCR allowed for the quantification of NHPB over the course of infection (Fig. 3). At 6 d postexposure, NHPB was not detected in the hepatopancreas, whereas the mean concentration of NHPB in feces of infected animals was 10 copies $\mathrm{mg}^{-1}$. At 16 and $23 \mathrm{~d}$ post-exposure, the mean amount of NHPB in the hepatopancreas was $3.1 \times 10^{6}$ copies $\mathrm{mg}^{-1}$ and in feces at $1.9 \times 10^{5}$ copies $\mathrm{mg}^{-1}$. NHPB was present at $1.2 \times 10^{7}$ copies $\mathrm{mg}^{-1}$ of hepatopancreas and $5.2 \times 10^{5}$ copies $\mathrm{mg}^{-1}$ of feces at $37 \mathrm{~d}$ post-exposure. 
The mean lethal load of NHPB was estimated in shrimp that died from NHPB infection as $2.6 \times 10^{7}$ copies $\mathrm{mg}^{-1}$ of hepatopancreas and $5.5 \times 10^{5}$ copies $\mathrm{mg}^{-1}$ of NHPB were present in feces (Fig. 4).

\section{Diagnostic sensitivity}

Histology, PCR, and real-time PCR were used to diagnose NHPB infection in juvenile Litopenaeus vannamei (Table 1). The earliest infections were detected by histology and real-time PCR. NHPB infection in L. vannamei was first detected in the hepatopancreas at $6 \mathrm{~d}$ post-exposure in paraffin embedded tissue stained with a modified Steiner-Steiner silver stain from 33.3\% of the shrimp examined. Additionally, NHPB was detected at low numbers in feces (10 copies $\left.\mathrm{mg}^{-1}\right)$ through real-time PCR at 6 d post-exposure, whereas it was first detected by PCR at $16 \mathrm{~d}$ post-exposure in the hepatopancreas and feces. At 23 d post-exposure, histology and real-time PCR detected an early NHPB stage I infection. Observed values of NHPB-positive diagnosis through various methods were not statistically different using Fisher's exact test (Quantitative Parasitology 2.0, Rozsa et al. 2000), though any difference may be difficult to detect due to low frequencies of positive samples. All control animals tested NHPB-negative through histology, PCR, and real-time PCR.

\section{DISCUSSION}

The NHP-bacterium infects hepatopancreatic cells. The hepatopancreas is the major digestive gland and

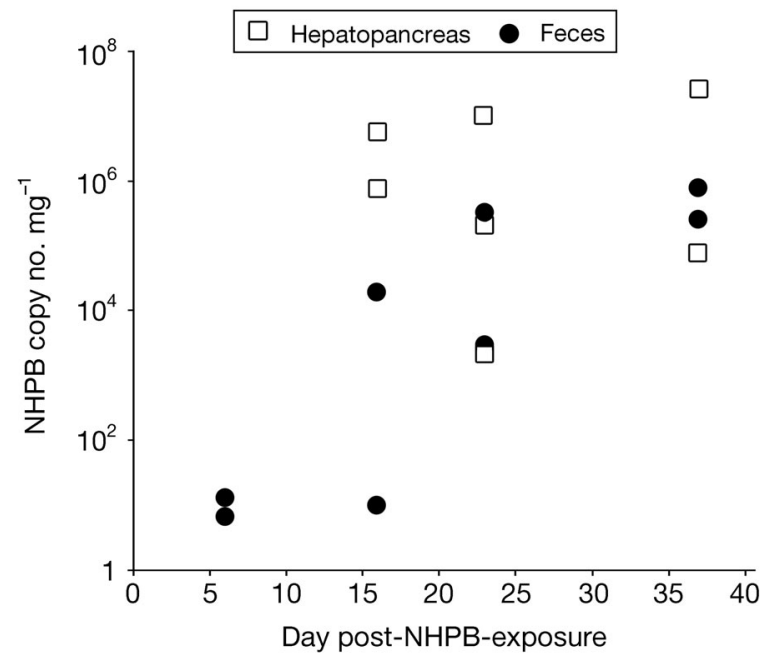

Fig. 3. Litopenaeus vannamei. Real-time PCR quantification of NHPB $\mathrm{mg}^{-1}$ of hepatopancreas and feces in experimentally infected shrimp randomly removed at intervals of $3,6,9,16,23,30,37,44$, and 53 d post-NHPB-exposure

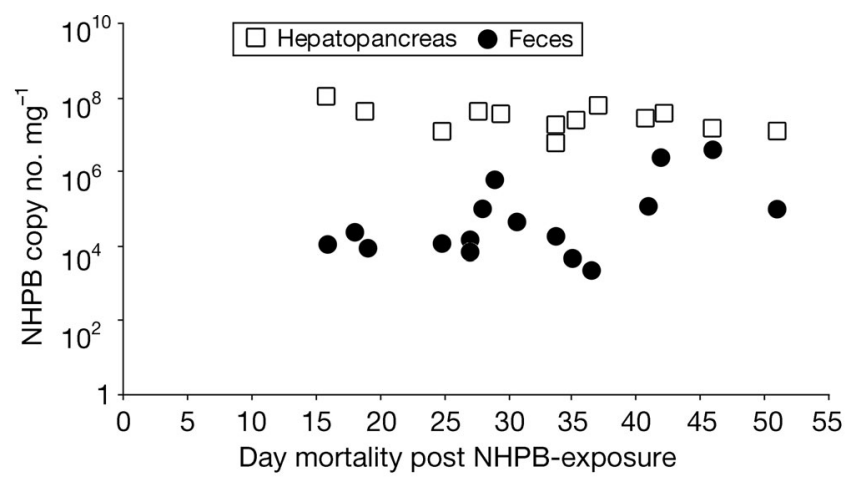

Fig. 4. Litopenaeus vannamei. Real-time PCR quantification of NHPB lethal load $\mathrm{mg}^{-1}$ of hepatopancreas and feces in experimentally infected shrimp experiencing NHPBinduced mortality

contains several cell types including E, R, F and B-cells (Gibson \& Barker 1979). E-cells characterized by mitotic activity are the source of the other cell types and are located at the most distal portion of the hepatopancreas (Vogt 1994). The most abundant type, R-cells, store lipid and glycogen, the least abundant type, F-cells, function in enzyme secretion, and B-cells function in intracellular digestion, nutrient accumulation, and transport of digestive material (Al-Mohanna \& Nott 1986, 1987).

Little is known of the mechanisms of pathogenesis of NHPB. However, we observed increased numbers of hepatopancreatic cells containing NHPB over the course of an infection, suggesting bacterial multiplication and spread is associated with increased tissue damage. In addition, all mature, but not the immature, hepatopancreatic cell types were observed to harbor NHPB in early infections. The occurrence of NHPB in mature cell types during early infection suggests no

Table 1. Litopenaeus vannamei. Comparison of histological and molecular methods for diagnosis of NHPB in individual shrimp hepatopancreas and feces over the course of NHPB infection. +: NHPB-positive result; -: NHPB-negative result. Six shrimp exposed per os to NHPB-infected tissue were randomly removed at intervals of $3,6,9,16,23,30,37,44$, and 53 d post-exposure

\begin{tabular}{|c|c|c|c|c|c|c|}
\hline \multirow[t]{2}{*}{ Day } & \multirow{2}{*}{$\begin{array}{c}\text { Shrimp } \\
\text { ID }\end{array}$} & \multicolumn{3}{|c|}{ _ Hepatopancreas __ } & \multicolumn{2}{|c|}{ _Feces _- } \\
\hline & & Histology & PCR & $\begin{array}{c}\text { Real-time } \\
\text { PCR }\end{array}$ & PCR & $\begin{array}{l}\text { Real-time } \\
\text { PCR }\end{array}$ \\
\hline 6 & 115 & + & - & - & - & + \\
\hline 6 & 145 & + & - & - & - & + \\
\hline 16 & 108 & + & + & + & - & + \\
\hline 16 & 120 & + & + & + & + & + \\
\hline 23 & 67 & + & - & + & - & - \\
\hline 23 & 171 & + & + & + & + & + \\
\hline 23 & 217 & + & + & + & + & + \\
\hline 37 & 15 & + & + & + & + & + \\
\hline 37 & 125 & + & + & + & + & + \\
\hline
\end{tabular}


preference for particular mature cells for development of infection. However, the lack of detectable NHPB in E-cells suggests that they may not be as suitable for infection as the other cell types.

The hepatopancreas, the only reported site of NHPB infection, and feces are the only shrimp materials presently used to diagnose an NHPB infection. The diagnosis of NHPB infection through molecular or histological testing of hepatopancreas tissue requires killing the animal suspected of carrying NHPB infection, whereas a non-destructive method of NHPB diagnosis in feces of live Litopenaeus vannamei broodstock was reported by Briñez et al. (2003). Additionally, we detected NHPB DNA in feces of live juvenile shrimp. The presence of NHPB DNA in feces indicates that the bacterium is shed from live animals into the pond environment and that feces may be a source of transmission of NHPB, although cannibalism of dead and dying NHPB infected shrimp is likely a natural source of new NHPB infections (Vincent et al. 2004). Analysis of fecal samples for diagnosis of NHPB infection may be applicable when examining expensive broodstock, but has limited application in a shrimp farm environment where sampling few juveniles for proper NHPB diagnosis will not affect overall production.

Because of the inability to culture NHPB by traditional bacteriological methods, there have been no previous determinations of NHPB load in infected animals. However, real-time PCR allows quantification of this unculturable bacterium. We estimated the amount of NHPB present in both hepatopancreas and feces of infected shrimp over the course of NHPB infection. The highest NHPB load was $8.9 \times 10^{7}$ bacteria $\mathrm{mg}^{-1}$ of hepatopancreas observed in a lethal infection. The amount of NHPB present in the hepatopancreas was higher than that observed in feces of the same individual.

The NHP disease stages as classified by Frelier et al. (1992) progressed over the course of infection. Through histological analysis, stages I and II were observed in shrimp displaying no overt signs of NHP disease. However, stage III NHP disease was observed in individuals displaying gross signs of NHPB infection. Additionally, all shrimp that experienced NHPBinduced mortality were in NHP disease stage III.

NHPB was first detected $6 \mathrm{~d}$ post-exposure, $10 \mathrm{~d}$ before observed mortality. A $25 \mathrm{mg}$ sub-sample of the hepatopancreas was excised and tested by PCR, whereas the remaining hepatopancreas was fixed for analysis by histology. This sub-sample is approximately one-tenth of the total hepatopancreas. Therefore, the failure to diagnose NHPB in infections sooner than $16 \mathrm{~d}$ post-exposure through PCR may be a factor of sub-sampling tissues for multiple diagnostic tests. In addition, the appearance of greater sensitivity in realtime PCR analysis of feces over hepatopancreas tissue may be attributed to more feces ( $250 \mathrm{mg}$ ) being tested than hepatopancreas $(25 \mathrm{mg})$ in molecular analyses.

In the time course analysis of NHPB, the absence of NHPB-positive animals $30 \mathrm{~d}$ post-exposure is likely the result of NHPB mortality. Mortalities from NHPB were observed from 16 to $51 \mathrm{~d}$ post-exposure with a peak at $34 \mathrm{~d}$. Therefore, the percent of NHPB-positive shrimp decreased over time due to mortality loss. Overall, only a quarter of the individuals exposed to NHPB-infected material were diagnosed as NHPB-positive, and this low percent of animals infected may be attributed to dose (Vincent et al. 2004).

The different sensitivities of diagnostic methods in the detection of NHPB infections before the onset of mortality demonstrates the necessity to use multiple diagnostic methods for appropriate diagnosis in the shrimp pond environment. The development of the real-time PCR procedure specific for NHPB creates opportunities to examine the effect of initial NHPB dose on transmission and mortality of infected individuals.

Acknowledgements. The authors thank V. Breland and M. Turner for technical assistance, and the 3 anonymous reviewers for comments regarding the manuscript. This research was partially funded by the United States Department of Agriculture, CSREES Grant Number 2002-38808-01381.

\section{LITERATURE CITED}

Al-Mohanna SY, Nott JA (1986) B-cells and digestion in the hepatopancreas of Penaeus semisulcatus (Crustacea: Decapoda). J Mar Biol Assoc UK 66:403-414

Al-Mohanna SY, Nott JA (1987) R-cells and digestive cycle in Penaeus semisulcatus (Crustacea: Decapoda). Mar Biol 95: 129-137

Bradley-Dunlop DJ, Pantoja C, Lightner DV (2004) Development of monoclonal antibodies for detection of Necrotizing Hepatopancreatitis in penaeid shrimp. Dis Aquat Org 60:233-240

Briñez B, Aranguren F, Salazar M (2003) Fecal samples as DNA source for the diagnosis of Necrotizing Hepatopancreatitis (NHP) in Penaeus vannamei broodstock. Dis Aquat Org 55:69-72

Frelier PF, Sis RF, Bell TA, Lewis DH (1992) Microscopic and ultrastructural studies of Necrotizing Hepatopancreatitis in pacific white shrimp (Penaeus vannamei) cultured in Texas. Vet Pathol 29:269-277

Gibson R, Barker PL (1979) The decapod hepatopancreas. Oceanogr Mar Biol Annu Rev 17:285-346

Jiang J, Temenak JJ, Richards AL (2003) Real-Time PCR duplex assay for Rickettsia prowazekii and Borrelia recurrentis. Ann N Y Acad Sci 990:302-310

Johnson SK (1990) Handbook of shrimp diseases. Tex A\&M Univ Sea Grant Coll TAMU-SG-90-601, College Station, TX

Krol RM, Hawkins WE, Overstreet RM (1991) Rickettsial and mollicute infections in hepatopancreatic cells of cultured Pacific white shrimp (Penaeus vannamei). J Invertebr Pathol 57:362-370

Lightner DV (1996) A handbook of pathology and diagnostic 
procedures for diseases of penaeid shrimp. Department of Veterinary Science, University of Arizona, Tucson, AZ

Lightner DV, Redman RM (1994) An epizootic of Necrotizing Hepatopancreatitis in cultured penaeid shrimp (Crustacea: Decapoda) in northwestern Peru. Aquaculture 122: 9-18

Lightner DV, Redman RM, Bonami JR (1992) Morphological evidence for a single bacterial etiology in Texas Necrotizing Hepatopancreatitis in Penaeus vannamei (Crustacea: Decapoda). Dis Aquat Org 13:235-239

Lotz JM, Flowers AM, Breland V (2003) A model of Taura Syndrome virus (TSV) epidemics in Litopenaeus vannamei. J Invertebr Pathol 83:168-176

Loy JK, Frelier PF (1996) Specific, nonradioactive detection of the NHP bacterium in Penaeus vannamei by in situ hybridization. J Vet Diagn Invest 8:324-331

Loy JK, Frelier PF, Varner P, Templeton JW (1996a) Detection of the etiologic agent of Necrotizing Hepatopancreatitis in cultured Penaeus vannamei from Texas and Peru by polymerase chain reaction. Dis Aquat Org 25:117-122

Loy JK, Dewhirst FE, Weber W, Frelier PF, Garbar TL, Tasca SI, Templeton JW (1996b) Molecular phylogeny and in situ detection of the etiologic agent of Necrotizing Hepatopancreatitis in shrimp. Appl Environ Microbiol 62: 3439-3445

Editorial responsibility: Timothy Flegel, Bangkok, Thailand
Pruder, GD, Brown CL, Sweeny JN, Carr WH (1995) High health shrimp systems: seed supply - theory and practice. In: Browdy, C.L. and Hopkins, J.S. (eds). Swimming through troubled water. Proc Spec Sess Shrimp Farming. World Aquaculture Society, Baton Rouge, LA, p 40-52

Rozsa L, Reiczigel J, Majoros G (2000) Quantifying parasites in samples of hosts. J Parasitol 86:228-232

Tang KFJ, Lightner DV (2001) Detection and quantification of infectious hypodermal and hematopoietic necrosis virus in penaeid shrimp by real-time PCR. Dis Aquat Org 44: 79-85

Varner PW (1998) Necrotizing Hepatopancreatitis: validation of an environmental PCR-based detection assay for use in descriptive epidemiologic studies. PhD dissertation, Texas A\&M University, College Station, TX

Vincent AG, Breland VM, Lotz JM (2004) Experimental infection of Pacific white shrimp Litopenaeus vannamei with necrotizing hepatopancreatitis (NHP) bacterium by per os exposure. Dis Aquat Org 61:227-233

Vogt G (1994) Life-cycle and functional cytology of the hepatopancreatic cells of Astacus astacus (Crustacea, Decapoda). Zoomorphology 114:83-101

Whelan JA, Russell NB, Whelan MA (2003) A method for the absolute quantification of cDNA using real-time PCR. J Immunol Methods 278:261-269

Submitted: March 2, 2005; Accepted: May 4, 2005 Proofs received from author(s): September 30, 2005 